\title{
Staging System
}

National Cancer Institute

\section{Source}

National Cancer Institute. Staging System. NCI Thesaurus. Code C18004.

A systematic method for clinicopathologic evaluation of tumors. 